\title{
LIFE15 ENV/IT/000392 - LIFE VITISOM Project, viticulture innovation technology and GHG emission monitoring
}

\author{
Leonardo Valenti ${ }^{1}$, Isabella Ghiglieno ${ }^{1,}{ }^{*}$, Federico Sambo ${ }^{1}$, Andrea Pitacco $^{2}$, Luca Tezza $^{2}$, Nadia Vendrame $^{2}$, \\ Giorgio Virgili ${ }^{3}$, Ilaria Minardi ${ }^{3}$, Elisabetta Giovenali ${ }^{3}$ and Jacopo LoBello ${ }^{3}$ \\ ${ }^{1}$ Università degli Studi di Milano, Dipartimento di Scienze Agrarie e Ambientali DiSAA, Via Celoria 2, 20133 Milano (Italy) \\ ${ }^{2}$ Università degli Studi di Padova, Dipartimento di Agronomia, Animali, Alimenti, Risorse naturali e Ambiente DAFNAE, Viale \\ dell'Università, 16, 35020 Legnaro (Italy) \\ ${ }^{3}$ West Systems S.r.l., Via Don Mazzolari, 2556025 Pontedera (Italy)
}

\begin{abstract}
The main aim of the LIFE VITISOM Project is to promote an innovative solution for the management of the organic fertilisation in the viticultural sector. In parallel, different activities of monitoring of impacts have been planned. Specifically, a deep study about GHG emissions has been organised. In this context, different studies are being carried out: a continuous monitoring of net carbon fluxes (NEE) through the Eddy Covariance method, followed by University of Padua which allows data to be obtained at vineyard ecosystem level; a spatial monitoring of $\mathrm{CH} 4, \mathrm{~N} 2 \mathrm{O}$ and $\mathrm{CO} 2$, through a mobile instrument for measuring the variation of GHG developed by West Systems within the LIFE+ IPNOA Project. In the first case, two Eddy Covariance towers have been installed, one at Guido Berlucchi (Franciacorta, Lombardy) and one at Bosco del Merlo (Lison, Veneto). Additionally, spatial monitoring is being carried out in five testing sites involved in the LIFE VITISOM project. In this case, different organic fertilisation managements are compared.
\end{abstract}

\section{Introduction}

\subsection{LIFE15 ENV/IT/000392 - LIFE VITISOM Project}

Financed in the context of the LIFE Program 2015, LIFE VITISOM (www.lifevitisom.com) started in July 2016. Coordinated by the University of Milan, in cooperation with seven other Italian partners, the Project's main aim is to introduce innovative technology for the distribution of organic fertilisers in vineyard, through the adoption of variable rate technology (VRT). In parallel, a very detailed study of impact derived from the use of organic matrices (manure, solid fraction of digestate and compost) in viticulture has been planned. Specific attention is being dedicated to the evaluation of GHG emissions both at ecosystem, in cooperation with the University of Padua, and at soil level thanks to the activities carried out by West Systems. The impact that fertilisation has in terms of $\mathrm{CH}_{4}$ and $\mathrm{N}_{2} \mathrm{O}$ [1] emissions is indeed well known. More information about $\mathrm{CO}_{2}$ exchange at the viticultural level would be of interest for further research on this subject.

\subsection{GHG and fertilisation in agriculture}

\footnotetext{
"Corresponding author: ighiglieno.vitisom@gmail.com
}

One of the most important environmental aspects to consider in the contribution of organic and mineral fertilizers is represented by the emission of greenhouse gases (GHG), due basically to the dispersion of nitrous oxide $\left(\mathrm{N}_{2} \mathrm{O}\right)$ in the atmosphere. Greenhouse gases are classified by their Global Warming Potential (GWP), a measure of a gas's capacity to contribute to the greenhouse effect, described as equivalents of $\mathrm{CO}_{2} ; \mathrm{N}_{2} \mathrm{O}$ being quite high, in comparison [2].

Nitrous oxide derives, in an agricultural environment, mainly from nitrification processes and denitrification or phenomena of immediate volatilization [1]. It is considered that about $1.975 \%$ of the nitrogen distributed through mineral fertilizer is dispersed in the form of this gas [3], even if the emissions are very variable, depending on the environmental conditions (temperature and humidity), the type of soil (availability of organic matter, $\mathrm{pH}$, level of compaction and texture) and the type of fertilizer applied [4].

Previous studies have, in fact, reported how important differences exist in terms of emissions between organic fertilizers and mineral fertilizers; in fact, the latter have an emission value of $\mathrm{N}_{2} \mathrm{O}$ about 10 times higher than that of organic ones, with an evident relationship to the different $\mathrm{C} / \mathrm{N}$ ratio and to the content in total nitrogen [5].

\subsection{The $\mathrm{CO}_{2}$ exchange at ecosystem level}


The study of vineyard carbon budget is a fundamental aspect of viticultural sustainability. The continuous monitoring of the net $\mathrm{CO}_{2}$ exchange (NEE) at the ecosystem level, including both soil and vine compartments, gives a quantification of the overall release/uptake of $\mathrm{CO}_{2}$ to/from the atmosphere [6]. This information is fundamental to assess the role of viticulture in the global GHG budget, taking into account not only respiration processes, but also the mitigation role played by plants through $\mathrm{CO}_{2}$ uptake by photosynthesis. Additionally, the combination of flux measurements at different scales (e.g. soil and ecosystem) is of great importance to implement efficient management of soil organic matter inputs to the system.

\section{Material and methods}

\subsection{Continuos monitoring of $\mathrm{CO}_{2}$ fluxes}

The monitoring of ecosystem $\mathrm{CO}_{2}$ fluxes was carried out from October 2016 to December 2017 at "Bosco del Merlo" (BM) and "Guido Berlucchi \& C." (GB) vineyards applying the eddy covariance (EC) technique.

Table 1. Description of vineyard where eddy covariance has been utilized

\begin{tabular}{|c|c|c|c|}
\hline Vineyard & $\begin{array}{c}\text { Plant } \\
\text { density }\end{array}$ & Cultivar & $\begin{array}{c}\text { Year of } \\
\text { planting }\end{array}$ \\
\hline GB & 10000 & Chardonnay & 2000 \\
\hline BM & 5000 & $\begin{array}{c}\text { Sauvignon } \\
\text { Blanc }\end{array}$ & 2001 \\
\hline
\end{tabular}

This method requires high frequency and simultaneous measurements of vertical wind velocity and $\mathrm{CO}_{2}$ concentration. At both sites, wind velocity components have been measured with a $3 \mathrm{D}$ sonic anemometer, while $\mathrm{CO}_{2}$ concentration with an Infrared Gas Analyzer (IRGA). Fast records $(10 \mathrm{~Hz})$ of vertical wind velocity $(w)$ and concentration $(c)$ are then used to calculate average 30-min fluxes, defined as the covariance between the fluctuations of $w$ and $c$. Even if measured at a point, the flux is representative of an upwind area of few hectares depending on atmospheric conditions.

\subsection{Spatial monitoring of GHG from soil treated with different organic fertilizers}

The spatial and temporal monitoring of Green House Gases (GHG), emitted directly from soil has been performed to monitor the impact of different organic matter management in terms of GHG emissions. The soil flux measurements were carried out by the use of the non stationary accumulation chamber technique. The measurements were performed in 5 vineyards located in different geographical areas of Italy: "Bosco del Merlo" in Veneto, "Berlucchi" and "Bonomi", both in Franciacorta, Lombardy, "Castelvecchi" in Tuscany and "Conte degli Azzoni" in Marche.
Table 2. Description of vineyard where spatial monitorings are being carried out

\begin{tabular}{|c|c|c|c|}
\hline Vineyard & $\begin{array}{c}\text { Plant } \\
\text { density }\end{array}$ & Cultivar & Description \\
\hline $\begin{array}{c}\text { Bosco del } \\
\text { Merlo }\end{array}$ & 5000 & Glera & $\begin{array}{c}\text { Plain vineyard } \\
\text { with high } \\
\text { extention }\end{array}$ \\
\hline Berlucchi & 10000 & Chardonnay & $\begin{array}{c}\text { High density } \\
\text { of planting }\end{array}$ \\
\hline Bonomi & 5500 & Chardonnay & $\begin{array}{c}\text { Terraced } \\
\text { vineyard }\end{array}$ \\
\hline Castelvecchi & 5000 & Sangiovese & $\begin{array}{c}\text { High sloped } \\
\text { vineyard }\end{array}$ \\
\hline Conti degli \\
Azzoni
\end{tabular}

The followings experimental plan was set:

- Not fertilised test, without tillage;

- Not fertilised test tilled;

- Distribution of compost not incorporated into the

soil;

- Distribution of compost incorporated into the soil;

- Distribution of manure not incorporated into the soil;

- Distribution of manure incorporated into the soil;

- Distribution of solid fraction of digestate not incorporated into the soil;

- Distribution of solid fraction of digestate incorporated into the soil;

Only for Bosco del Merlo testing site a test fertilised with urea (with and without incorporation into the soil) was set.

The GHG monitored are $\mathrm{N}_{2} \mathrm{O}, \mathrm{CO}_{2}$, and $\mathrm{CH}_{4}$, which were measured and georeferred at the same time for each sampling point. During 2017, the measurements carried out for each monitoring campaign and for each vineyard, were: 128 in "Bosco del Merlo", 115 in "Bonomi", 128 in "Berlucchi", 156 in "Bosco del Merlo" and 128 in "Castelvecchi". Moreover, in each vineyard, GHG fluxes were evaluated for the three different organic fertilizers: compost, digestate and manure.

The monitoring activity started in January 2017; the first campaign was carried out in order to define a GHG background value and it was performed before the fertilization treatments.

After this, the following planned monitoring campaigns

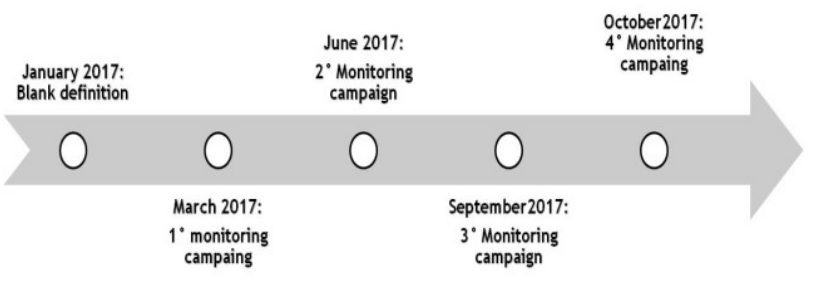

Fig. 1. Timeline of GHG monitoring campaigns in 2017 
for each site were focused on:

- The identification of the peak emission value for $\mathrm{N}_{2} \mathrm{O}$. For this reason, a monitoring campaign was carried out within 10 days after the fertilization;

- Highlighting seasonal variation in spatial emissions of GHG. For this, GHG monitoring was repeated in each vineyard in different periods of the years (Fig.1).

A mobile instrument for measuring the variations of the emissions of greenhouse gases (GHG) was used.

This instrument, developed within IPNOA Project by West Systems, can rapidly measure $\mathrm{N}_{2} \mathrm{O}, \mathrm{CO}_{2}$, and $\mathrm{CH}_{4}$ emissions from the soil. The instrumentation is housed on a light-tracked vehicle with electric battery-powered traction. This vehicle can be driven remotely thanks to a remote control device that reproduces the control plank and facilitates manoeuvring. Given that it is portable, the instrument can measure emissions directly in the field from different plots. Realtime data can be viewed directly on a smartphone via a dedicated application named FluxManager. This handles data acquisition from sensors, the graphical display, data saving, and georeferencing of measures thanks to the GPS/ GLONASS.

\section{Results and discussion}

\subsection{Continuous monitoring of $\mathrm{CO}_{2}$ fluxes}

Total monthly carbon fluxes from October 2016 to December 2017 are presented in Fig. 2.

In this plot, positive fluxes indicate release of $\mathrm{CO}_{2}$ to the

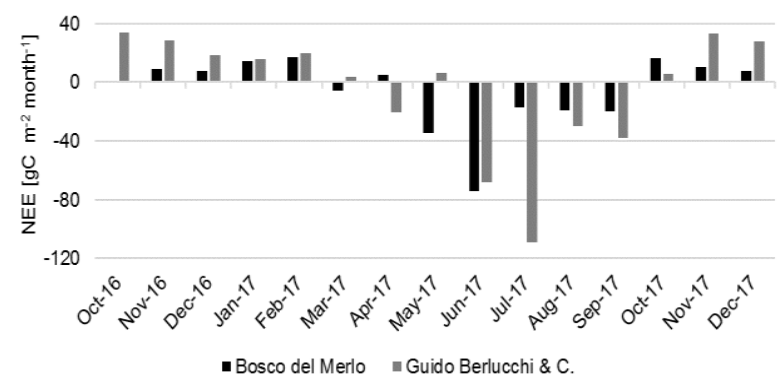

Fig. 2. Monthly net carbon fluxes (NEE) at "Bosco del Merlo" (black) and "Guido Berlucchi\& C." (grey) vineyards.

atmosphere, while a negative value means that the vineyard absorbed $\mathrm{CO}_{2}$ and photosynthesis was prevailing over respiration.

During autumn and winter, fluxes were generally positive at both sites, as results of vine dormancy period and low activity of inter-row herbaceous vegetation. However, $\mathrm{CO}_{2}$ release was higher at $\mathrm{GB}$ vineyard from October to December 2016 due to inter-row soil tillage and disruption of the grass cover. Indeed, at BM, the NEE in October was almost zero, indicating that grass photosynthesis and respiration were in balance.

In spring, GB vineyard started to act as carbon sink earlier than BM, but in late April it was impacted by a late frost, that strongly damaged the grapevines. This event, together with soil tillagecaused the vineyard to be an overall source of carbon in May. After, in June and
July, the vineyard reached its maximum uptake, with NEE over $-100 \mathrm{gC} \mathrm{m}^{-2} \mathrm{month}^{-1}$. However, in August, elevated air temperature, together with disruption of inter-row grass due to soil cultivation, substantially reduced vineyard carbon absorption.

The BM vineyard was less affected by the late frost and it started to act as carbon sink in May, showing a similar $\mathrm{CO}_{2}$ uptake to that of GB in June. In late June, part of the vineyard was regrafted and the uptake in the following months considerably decreased. At the end of

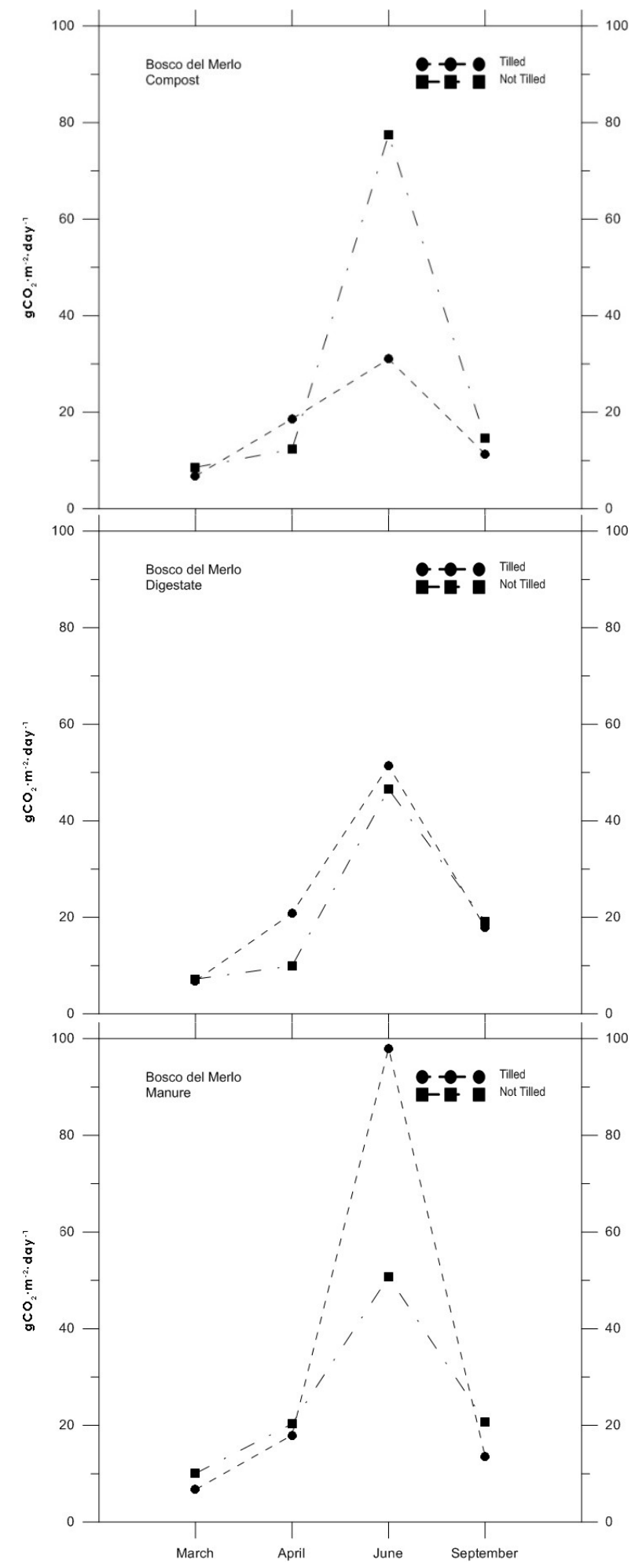

Fig. 3. Seasonal $\mathrm{CO}_{2}$ emissions in Bosco del Merlo in 2017 for compost, solid fraction of digestate and manure. 
the study period, the net carbon balance of the two vineyards was quite similar with a net uptake around -82 $\mathrm{gC} \mathrm{m}^{-2}$ at $\mathrm{BM}$ and $-73 \mathrm{gC} \mathrm{m}^{-2}$ at $\mathrm{GB}$, even if the pattern of monthly fluxes was different at the two sites.

\subsection{Spatial monitoring of GHG emissions}

The collected data, regarding 2017 sampling period, was elaborated and, for each vineyard, GHG emitted in correspondence with the different organic fertilizer was calculated.

To calculate the emissions value, expressed as grams of $\mathrm{GHG} / \mathrm{m}^{2} /$ day, the Upper Confidence Limit (UCL) was adopted. UCL is a value which represents a good estimation of the mean of a population (data set) and represents a realistic number that can occur in practice and a good estimation of grams of gases emitted for compost, or digestate, or manure. UCL was calculated for the different areas of the vineyard treated with compost, digestate and manure.

In Fig. 3 the $\mathrm{CO}_{2}$ fluxes monitored in 2017 at Bosco del Merlo are shown. In this plot, the $\mathrm{CO}_{2}$ emissions trend is shown in different periods of the year and for each of the organic fertilizers. It is possible to observe an increase of $\mathrm{CO}_{2}$ emissions and a peak value in June, probably due to the correlation with the increase of temperature.

The highest $\mathrm{CO}_{2}$ emissions were calculated in June for manure, in non tilled area, with a value of almost 100 grams of $\mathrm{CO}_{2} \mathrm{~m}^{-2}$ day $^{-1}$. Good results have been obtained for digestate, where emissions values are lower than the ones obtained for the other organic fertilizers and for digestate applied in not tilled area.

\section{Conclusion}

We showed that vineyard management (e.g. soil cultivation, canopy management) had a strong impact on the carbon balance, reducing $\mathrm{CO}_{2}$ uptake. However, the variability between the two sites can also be attributed to different climatic conditions and vineyard characteristics.

Regarding spatial emissions data results, the statistical analysis will be carried out for each vineyard as well as for $\mathrm{N}_{2} \mathrm{O}$ emissions. Preliminary results for Bosco del Merlo show digestate, tilled and not tilled, having less impact on $\mathrm{CO}_{2}$ emissions while manure seems to be the "worst case". The monitoring activity will continue for 2018 and more data for every vineyard will be collected in order to better highlight how organic fertilizer has less impact of the emission of GHGs.

\section{References}

1. IPCC, Guidelines for National Greenhouse Gas Inventories -National Greenhouse Gas Inventories Programme and Institute for Global Environment Strategies, 4 (2006)

2. IPCC, Greenhouse gas protocol: Global Warming Potential - Attached of Fourth Assessment of the
Intergovernmental Panel on Climate Change (2007)

3. C. Georget, Le Vigneron Champenois, 8, 70-81 (2009)

4. H. Patak, Current science, 77, 3, 359-369 (1999)

5. C. Georget, O. Garcia, A. Descôtes, Le Vigneron Champenois, 8, 55-63 (2012)

6. M. Aubinet, A. Grelle, A. Ibrom, U. Rannik, J. Moncrieff, T. Foken, A.S. Kowalski, P.H. Martin, P. Berbigier, C. Bernhofer, R. Clement, J. Elbers, A. Granier, T. Grünwarld, K. Morgenstern, K. Pilegaard, C. Rebmann, W. Snijders, R. Valentini, T. Vesala, Adv. Ecol. Res. 30, 113-175 (2000) 